\title{
Journal of

\section{Thermolytic synthesis of graphitic boron carbon nitride from an ionic liquid precursor: mechanism, structure analysis and electronic properties}

\author{
Tim-Patrick Fellinger, ${ }^{* a}$ Dang Sheng Su, ${ }^{b}$ Markus Engenhorst, ${ }^{c}$ Devendraprakash Gautam, ${ }^{c}$ Robert Schlögl $^{b}$ \\ and Markus Antonietti ${ }^{a}$
}

Received 9th July 2012, Accepted 25th September 2012

DOI: 10.1039/c2jm34486f

Recent work has shown the potential of ionic liquids (ILs) as a precursor for porous networks and nitrogen doped carbon materials. The combination of liquid state and negligible vapour pressure represents almost ideal precursor properties and simplifies the processing drastically. Here, we extend this work to get a deeper insight into the solid formation mechanism and to synthesize a mixed boron carbon nitride species by the thermolysis of $N, N^{\prime}$-ethylmethylimidazolium tetracyanoborate (EMIMTCB), a well-known boron- and nitrogen-containing IL. In contrast to other molecule pyrolysis routes boron carbon nitride shows the average composition " $\mathrm{BC}_{3} \mathrm{~N}$ " and like other IL-derived materials turns out to be distorted graphitic, but thermally and chemically very stable, and possesses favourable electrical properties. The detailed mechanistic investigation using TG-IR, FT-IR, solid-state NMR, Raman, WAXS, EELS, XPS and HRTEM also contributes to the general understanding of IL-based material formation mechanisms.

\section{Introduction}

The introduction of secondary lightweight elements, such as nitrogen or boron, into the chemical structure of carbon alters its properties, depending on the heteroatom amount and the nature of bonding. It is well known that the introduction of boron or nitrogen into a pool of $\mathrm{sp}^{2}$-bonded graphitic carbon atoms leads to distinctly different carbon material properties. Improved electrical conductivity and increased chemical stability are just two of the potential benefits. ${ }^{1}$ Structural nitrogen (incorporated into the graphitic sheets) shows high impact on the physical properties of the final carbon material. A very popular property amplification achieved by such nitrogen introduction is the increase of electrical conductivity. ${ }^{2-5}$ Doping with the electron rich nitrogen atoms modifies the band structure of the material. ${ }^{6}$ The valence band is lowered, thus the material is chemically more stable, and the electron density at the Fermi level increases. This has experimentally been shown to induce a metallic character in nitrogen-doped CNTs. ${ }^{7}$ Practical observations could also be supported by quantum mechanical calculations by Carvalho and Santos. ${ }^{8}$

The simultaneous incorporation of boron and nitrogen into graphitic carbon to give $\mathrm{B} / \mathrm{N}$-doped carbon to boron carbon

${ }^{a}$ Max-Planck-Institute of Colloids and Interfaces, Department of Colloid Chemistry, Am Mühlenberg 1, 14424 Potsdam-Golm, Germany. E-mail: Fellinger@mpikg.mpg.de

${ }^{b}$ Fritz-Haber-Institut, Department of Inorganic Chemistry, D-14195 Berlin, Germany

'University of Duisburg-Essen, Faculty of Engineering and Center for Nanointegration Duisburg-Essen (CeNIDE), D-47057 Duisburg, Germany nitrides is of some interest as well. The influence of the addition of $\mathrm{sp}^{2}-\mathrm{BN}$, which is isoelectronic to graphitic carbon, on the physical properties should allow the successive alteration of properties between graphite and hexagonal boron nitride (h-BN). Indeed it is known that boron and nitrogen containing graphitic compounds reveal semiconducting properties combined with a lower band gap compared to pure h-BN. ${ }^{9}$ For $\mathrm{B} / \mathrm{N}$-doped carbons or boron carbon nitrides, appealing properties like an adjustable band gap were also reported. ${ }^{\mathbf{1 0}}$

Nitrogen doping also leads to an increase in material basicity. While layer edge chemical nitrogen functionalities give rise to a Brønsted-basicity due to e.g. amine groups, structural nitrogen induces an increasing Lewis-basicity, which tailors nitrogendoped carbon materials for applications in catalysis. ${ }^{11}$ Recent reports have shown that porous carbon with structurally integrated nitrogen acts as an inexpensive and metal-free catalyst in the oxygen reduction reaction (ORR), used in PEMFCs. ${ }^{12}$ The ionic character of the $\mathrm{BN}$ bond and the mechanical stress induced by incorporated $\mathrm{sp}^{2}$ - $\mathrm{BN}$ moieties into graphitic carbon are expected to extend those properties for chemoselective sorption purposes and metal-free catalytic applications. ${ }^{13,14}$ Recent reports have also demonstrated the potential applicability of boron-doped catalytic materials for ORR. ${ }^{13-15}$

In situ processes that derive the final material directly from nitrogen-rich precursors, either by thermolysis or pyrolysis or by chemical vapour deposition (CVD) are the main synthesis routes to nitrogen-doped carbons with high contents of structural nitrogen. ${ }^{13-18}$ Commonly used precursors are aminosugars, ${ }^{19}$ melamine, ${ }^{20,21}$ benzylamine, ${ }^{22}$ nitrogen containing heterocycles ${ }^{6,23,24}$ or phthalocyanines. ${ }^{25}$ 
The synthesis, structure and electrical properties of graphitic B-C-N materials have been established through research work in over 2000 papers including the first observation of highly crystalline graphitic $\mathrm{BCN}, \mathrm{BC}_{2} \mathrm{~N}$ and $\mathrm{BC}_{3} \mathrm{~N}$ by heating a mixture of carbon black and boron in an atmosphere of nitrogen or ammonia at temperatures of $1800-2000{ }^{\circ} \mathrm{C}$. These include the synthesis of graphitic $\mathrm{BCN}$ compounds by high temperature treatment of a mixture of graphite and boron in an atmosphere of nitrogen, ${ }^{26}$ the synthesis of semiconductive graphitic $\mathrm{B}_{x} \mathrm{C}_{y} \mathrm{~N}_{x}$ by $\mathrm{CVD}$ of a mixture of $\mathrm{BCl}_{3}, \mathrm{C}_{2} \mathrm{H}_{2}$ and $\mathrm{NH}_{3}$ at $400-700^{\circ} \mathrm{C}$, ${ }^{9}$ the synthesis of semiconductive graphitic $\mathrm{BCN}, \mathrm{BC}_{2} \mathrm{~N}$ and $\mathrm{BC}_{3} \mathrm{~N}$ by CVD of volatile nitriles and $\mathrm{PAN}$ with $\mathrm{BCl}_{3}$ at $400{ }^{\circ} \mathrm{C}$ and $1000^{\circ} \mathrm{C}$, the synthesis of graphitic $\mathrm{BCN}$ from pyrrolidine-borane complex ${ }^{27}$ and many others. ${ }^{28-30}$ The different approaches may be summarized as solid-gas reactions, ${ }^{26,31} \mathrm{CVD}$ methods, ${ }^{1,9,32}$ or as pyrolysis. ${ }^{27-29,33}$ It has to be noted that in the younger literature $\mathrm{BCN}(\mathrm{O})$ materials were named boron carbon nitrides as well. In the field of boron carbon nitrides there is less research on bulk materials but more focus on nanostructures such as boron and nitrogen enriched graphenes ${ }^{34-36}$ and nanotubes, ${ }^{37,38}$ pseudographenes and $\mathrm{BCN}$ nanotubes. ${ }^{39,40}$ Much less has been reported on porous bulk BCN materials, showing the difficulty of modulating the shape of such materials. ${ }^{41}$ Thermolysis of selfassembled block-co-polymers ${ }^{42}$ and hard templating based on porous silicas in a CVD setup ${ }^{43}$ lead to the formation of mesoporous BCN materials. Portehault et al. recently reported on mesoporous BCN and its extraordinary hydrogen storage. ${ }^{41,44}$ Wang et al. have recently applied boron-doped carbon nitride as a metal-free catalyst for aliphatic $\mathrm{C}-\mathrm{H}$ bond oxidation. ${ }^{45}$

However, it is not in the scope of this article to review synthetic approaches or mechanistic details in the formation of boron carbonitride structures in general. Herein, we want to put emphasis on the very topical and emerging field of using task-specific ionic liquids (TSILs) as direct material precursors. The present article deals with solid formation by thermolysis of the boron, carbon and nitrogen containing ionic liquid $N, N^{\prime}-$ ethylmethylimidazolium tetracyanoborate (EMIM-TCB) leading to a new bulk boron carbon nitride. Only very few, and mostly nitrile-containing ILs, do not decompose exclusively into gaseous products and this study allows for an understanding of the general aspects of this phenomenon. The presented synthesis can be ranked as another pyrolysis approach of a molecular precursor containing B, C and N. Interestingly the presented synthesis results in graphitic $\mathrm{BC}_{3} \mathrm{~N}$, while such attempts usually lead to graphitic boron carbonitrides of stoichiometry BCN. ${ }^{27-30}$

Recently, we and others employed carbonisable (e.g. nitrile containing) ionic liquids (ILs) as direct precursors for the synthesis of bulk materials such as nitrogen-doped carbon ${ }^{16-18,46,47}$ and sulphur-doped carbon..$^{47}$ Carbons with nitrogen contents as high as $10.4 \%$ with an electronic conductivity superior to graphite and an oxidation stability exceeding carbon nanotubes were obtained. ILs have the advantage that they are both liquid and - due to the salt-like structure - exhibit a negligible vapour pressure. ${ }^{48,49}$ Therefore, no pressure has to be applied, making the synthesis facile and free of high technical efforts. In addition, the ILs show strong interaction with inorganic surfaces and a connected very good wettability. Because of this, the IL precursor may be dip-coated, spun, printed, sprayed or templated towards flexible shapes with a resolution down to the nanometer-range before or throughout conversion to the final nitrogen-doped carbon in simple inert gas ovens. ${ }^{16}$ Very recently the use of the IL precursor enabled us for a breakthrough in the synthesis of high surface area materials. The high thermal stability combined with the ionic character of the starting material allows for the condensation reaction within an inert inorganic salt melt. Simple phase separation in the proceeding reaction allows the inorganic salt to act as a porogen leading to high surface area materials after washing with water. ${ }^{50}$

Interestingly, IL-based carbon materials occur with a comparably low crystalline order, but nevertheless with impressive properties like electrical conductivity and stability, where a high local order is expected to be important. Commonly, ILs are chosen in a way that the cation already contains structural nitrogen, e.g. pyridinium, pyrrolidinium or imidazolium, while the anion preferentially carries cyano-functionalities, because only a few, and in particular cyano-containing ILs, give high carbon yields without the application of pressure or nanoconfinement. ${ }^{47}$ The current understanding is that cyano-groups promote the first condensation step towards a resin with preorganization and high thermal stability, which then carbonises under elimination of low molecular weight compounds, minimising fragmentation reactions of the scaffold.

From the viewpoint of synthesis, IL carbonisation is fairly different from other pyrolysis approaches. First of all, the ionic character itself promotes the formation of carbonaceous products as no evaporative loss of precursors occurs until the elimination temperature is reached. Carbonisation experiments with the uncharged relatives of the IL precursors have usually resulted in no solid yield. On the basis of the chemical characterisation of volatile decomposition products via coupled thermogravimetric analysis and mass spectrometry, but also infrared (IR) and nuclear magnetic resonance (NMR) spectroscopy and elemental analysis, a condensation scheme could recently be elaborated. ${ }^{17}$ Initiated either by reverse Menschutkin reaction or alkyl fragmentation, a nucleophilic attack of dicyanamides on aromatic cations together with triazine formation due to cycloaddition leads to a branched, polymer-like network, which subsequently further eliminates side groups to restructure into the final graphitic nitrogen-doped carbon. However, there are discussions in the literature about the required composition of ILs to improve the generation of solid carbonaceous material, leaving space for more detailed investigation on the mechanism of solid formation. ${ }^{17,46}$

Structure, local order or crystallinity, is investigated by applying wide-angle X-ray scattering (WAXS) and high resolution transmission electron microscopy (HRTEM). The chemical composition and electronic properties of the material are determined via Raman spectroscopy, electron energy loss spectroscopy (EELS), nuclear magnetic resonance (NMR), and X-ray photoelectron spectroscopy (XPS). Thermogravimetric analysis coupled with infrared spectroscopy and elemental analysis is further used to investigate the mechanism of solid formation. Finally, electronic conductivity is determined on spark plasma sintered monolithic species.

Successful production of various highly porous carbons using templating strategies has already been reported, ${ }^{18}$ enabling testing of these materials in applications (i.e. supercapacitors or 
electrocatalysis) where high specific surface area and structurally defined porosity are a necessity.

\section{Result and discussion}

\section{(1) Mechanistic experiments}

The synthesis of boron- and nitrogen-rich carbon or boron carbon nitrides was performed using the ionic liquid 1-ethyl-3methylimidazolium-tetracyanoborate (EMIM-TCB; Fig. 1a) as a direct boron, carbon and nitrogen precursor. As a reference for direct comparison, we chose EMIM-dca (Fig. 1b) as a precursor for the generation of solely nitrogen containing carbon.

As EMIM-TCB is structurally close to well-understood IL precursors, ${ }^{17,46}$ it is worth having a detailed look on the mechanistic differences. To compare EMIM-TCB with EMIM-dca, coupled thermogravimetric analysis (TGA) and differential scanning calorimetry (DSC) measurements under nitrogen gas were applied (Fig. 2). Characteristic temperatures for the TGA measurement were evaluated from the first derivative of the mass loss with temperature.

The exothermic decomposition of EMIM-TCB sets in at around $250{ }^{\circ} \mathrm{C}$, reaching a maximum heat flow at $416{ }^{\circ} \mathrm{C}$ (see DSC). The exothermic reaction leads to a strong mass loss of $\sim 50 \%$ reaching its maximum at $416^{\circ} \mathrm{C}$ in agreement with the calorimetric results (see DSC). In context with the starting decomposition, an endothermic peak can be observed at $425^{\circ} \mathrm{C}$ in the calorigram. Obviously, the decomposition creates volatile species, but leaves reactive non-volatile fragments, which subsequently condensate to form the glassy, black solid. Potentially, the ionic character is retained and facilitates the formation of solid materials due to Coulombic interaction. A second endothermic decomposition/condensation step sets in at $\sim 431{ }^{\circ} \mathrm{C}$, reaches the maximum heat flow at $462{ }^{\circ} \mathrm{C}$ and causes a weaker mass loss of $\sim 10 \%$ at $462{ }^{\circ} \mathrm{C}$ (TGA). This second reaction creates a comparably broad peak, which seems to contain other distinct peaks, emerging as weak shoulders. The broadening may be explained either by an overlapping of co-occurring/consecutive reactions or by mobility-constricted reactions. The mentioned reaction(s) occurs in a rather viscous or a glass-like state, which only offers certain mobility. Across the higher temperature range, a further small but steady mass loss can be observed. At $1000{ }^{\circ} \mathrm{C}$, a shiny black solid residue is obtained in $25.5 \%$ yield.

The already well-investigated pyrolysis of EMIM-dca sets in with an endothermic peak already at $205^{\circ} \mathrm{C}$ reaching a maximum heat flow at $321^{\circ} \mathrm{C}$ (see DSC). The endothermic reaction leads to a first mass loss of $\sim 40 \%$ reaching its maximum at $321{ }^{\circ} \mathrm{C}$ in
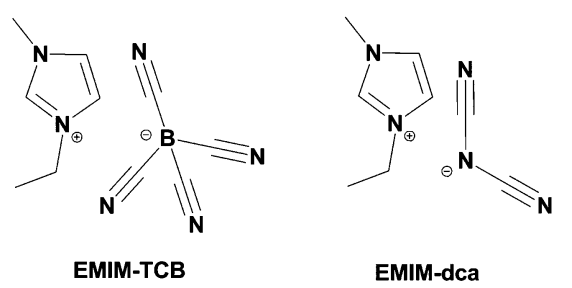

Fig. 1 Molecular structure of $N, N^{\prime}$-ethylmethyl-imidazolium-tetracyanoborate (EMIM-TCB) and $N, N^{\prime}$-ethylmethyl-dicyanamide (EMIMdca).
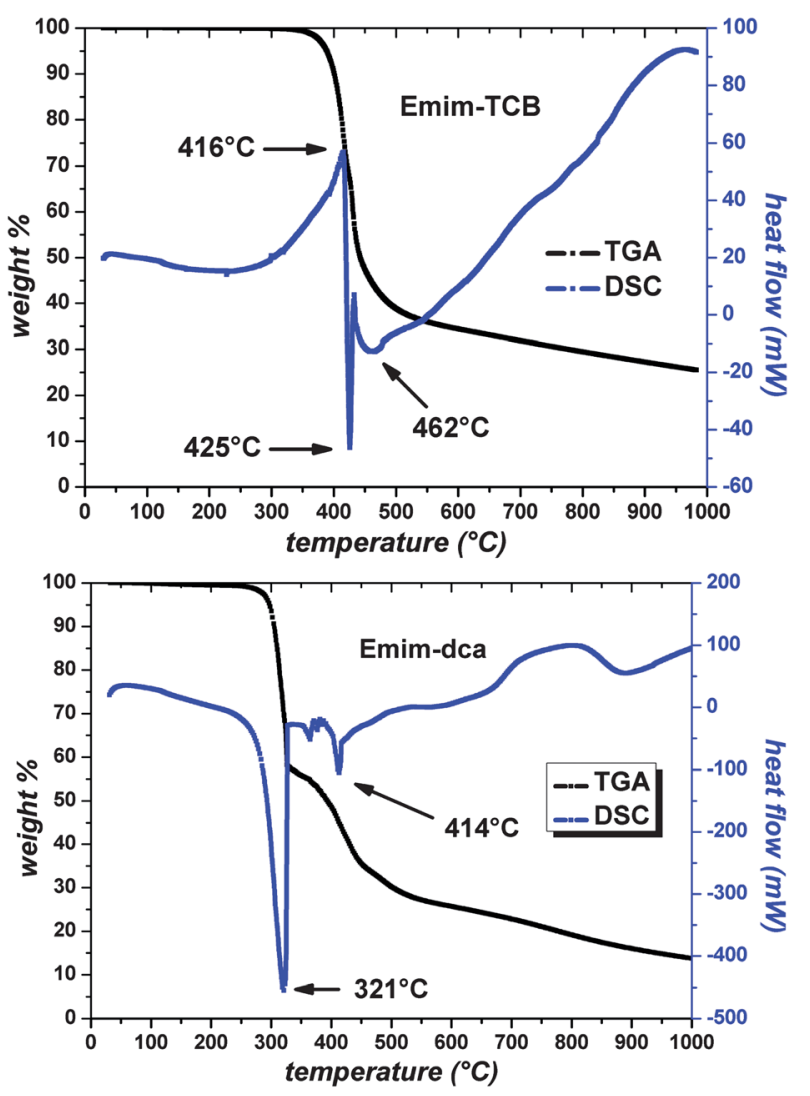

Fig. 2 TGA/DSC analysis between 0 and $1000{ }^{\circ} \mathrm{C}$ of EMIM-TCB (up) and EMIM-dca (down) under nitrogen gas.

agreement with the calorimetric results (see DSC). Two more endothermic peaks occur at the temperatures of $365^{\circ} \mathrm{C}$ and 414 ${ }^{\circ} \mathrm{C}$ leading to a second mass loss of another $30 \%$. Like for EMIM-TCB, an ongoing small but steady mass loss can be observed with further increasing temperatures, in contrast to EMIM-TCB accompanied by an exothermic broad shoulder between $700{ }^{\circ} \mathrm{C}$ and $900{ }^{\circ} \mathrm{C}$. At $1000{ }^{\circ} \mathrm{C}$ the thermal decomposition yields $13.6 \%$ residual mass.

Despite the increased pyrolysis yield of EMIM-TCB and the almost opposite enthalpic behaviour to EMIM-dca, another remarkable difference is the characteristic decomposition temperature of $416^{\circ} \mathrm{C}$, which is - compared to $315^{\circ} \mathrm{C}$ - strongly shifted to higher temperatures. Obviously, the cyanido complex with the less electronegative boron leads to a reduced decomposition tendency as compared to the covalently nitrogen bound derivative i.e. dicyanamide. As the first DSC signals in both cases are directly accompanied with mass loss, the proposed cycloaddition sets in after first elimination steps creating unsaturated fragments. However, the exceptional stability of EMIM-TCB opens the possibility to come even closer to the regime of $\mathrm{C}-\mathrm{C}$ bond pyrolysis within the liquid phase, where mobility compared to typical solid state pyrolysis reactions is highly increased. This opens up a completely different reaction channel, as is further discussed below.

The broad interests in the thermostability of ionic liquids lead to some investigations on decomposition reactions. The mainly reported decomposition pathway of liquid ionic cyanides is the reverse Menschutkin reaction, where e.g. the dicyanamide is 
alkylated under formation of volatile $N$-alkylimidazole. ${ }^{16-18,51}$ The maximally coordinated and therefore non-nucleophilic and very stable TCB anion is much less reactive in that sense, i.e. this reaction can set in at $100{ }^{\circ} \mathrm{C}$ later, at best.

Ohtani et al. investigated thermal decomposition behaviours of other imidazolium-type ionic liquids. ${ }^{52}$ According to their results there are generally two pathways. The first pathway is the dealkylation of $N, N^{\prime}$-dialkylimidazolium via Hofmann elimination to form volatile alkenes and $N$-alkylimidazole i.e. ethene and $N$-methylimidazole in the case of EMIM. Within the second pathway, nucleophilic anions undergo reverse Menschutkin reaction as described for cyano-containing ILs. Interestingly, in all described cases the imidazole ring structure is retained at $550{ }^{\circ} \mathrm{C}$, underlining its remarkable stability. Methylated rings are more common decomposition products than ethylated ones. However, the preferred course is dependent on the nature of the anions. In the case of non-nucleophilic anions, such as fully coordinated complexes i.e. $\mathrm{PF}_{6}{ }^{-}$and $\mathrm{BF}_{4}{ }^{-}$, the anion needs to decompose into reactive derivatives to initiate one of the pathways. Unfortunately, the fact that the anion needs to act as proton abstracting base to induce Hofmann elimination is poorly discussed. Therefore, ionic liquids with less nucleophilic, but rather Brønstedt basic anions, preferentially decompose via pathway one, while rather nucleophilic anions lead to path II, the reverse Menschutkin reaction.

The TCB anion, which was first described in year 2000, shows exceptional stability, presumably coming from the only weak electrophilicity of the cyano-C atom. ${ }^{53,54} \mathrm{Küppers}$ et al. reported on tetracyanoboric acid $\mathrm{H}\left[\mathrm{B}(\mathrm{CN})_{4}\right]$ to be a strong acid, implying weak basicity of the anion due to the acid-base theory. The colourless acid, a powder, decomposes under release of $\mathrm{HCN}$ to a brownish polymeric compound of the stoichiometry $\left[\mathrm{B}(\mathrm{CN})_{3}\right]_{n}{ }^{55}$ Without acid, the very stable, non-nucleophilic nature of the TCB anion and the weak basicity can explain the onset of decomposition at very high temperatures, and the anion pyrolysis should initiate the decomposition. This transfers the overall reaction to the temperature regime of general $\mathrm{C}-\mathrm{C}$ bond pyrolysis.

As related research is currently rather focused on ionic liquids as solvents, ${ }^{56,57}$ the further steps of condensation and rearrangement reactions towards whole solid material formation are much less analyzed. For cyano-containing ILs, cyclotrimerisation to form triazines is expected to be crucial before rearrangements and release of functional groups leads to further carbonisation. In agreement with the usually observed reverse Menschutkin reaction and Hofmann elimination the weakest single bond, which is the $\mathrm{C}-\mathrm{N}$ bond is expected to break first. Imidazole fragments thereby may be incorporated into a triazine network, explaining the influence of the cations on the final product composition, but not why the same anions with other cations do not generate carbonization yield at all.

Thermodynamically the cleavage of the $\mathrm{B}-\mathrm{C}$ bonds should lead to stronger $\mathrm{B}-\mathrm{N}$ bonds by increasing the temperature. However, the cyano-boron bond within the TCB anion is exceptionally stable. It has to be mentioned that the energetically favoured B-O bond $\left(\sim 540 \mathrm{~kJ} \mathrm{~mol}^{-1}\right)$ - explaining the strong oxophilicity of boron - usually leads to $\mathrm{BCN}(\mathrm{O})$ materials at temperatures below $900{ }^{\circ} \mathrm{C}$. Even attentive exclusion of oxygen during the synthesis still ends in the formation of metastable

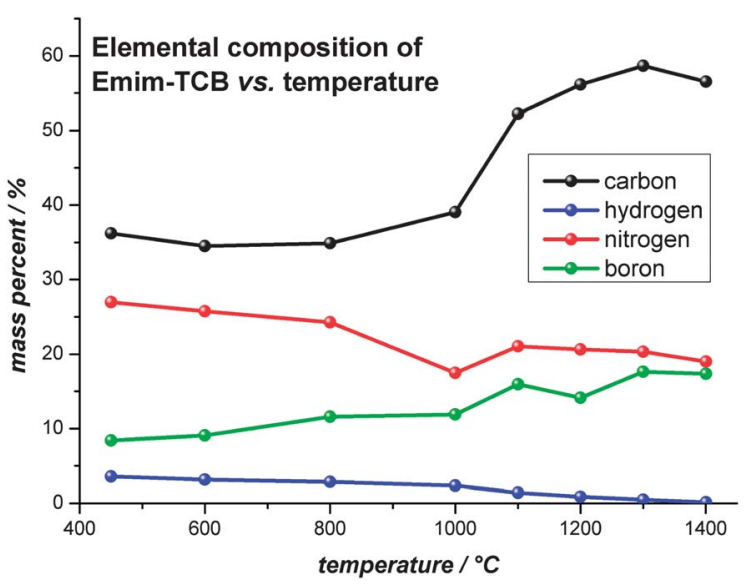

Fig. 3 Elemental composition (BCHN) of the pyrolysis products of EMIM-TCB at increasing synthesis temperatures.

compounds, which oxidise after cooling in the presence of oxygen/water. Therefore, a reshuffling from $\mathrm{B}-\mathrm{C}$ to $\mathrm{B}-\mathrm{N}$, but also to $\mathrm{B}-\mathrm{O}$ bonds after splitting of the cyanide from the boron is to be considered.

To aid elucidation of the reaction mechanism in our specific case, EMIM-TCB was heated under nitrogen gas flow to different temperatures (heating rate: $10 \mathrm{~K} \mathrm{~min}^{-1}$, isothermal period at $T_{\max }$ for 1 hour) and analysed towards the B, C, N and $\mathrm{H}$ elemental composition of the product (Fig. 3). The glassy solid product of the first decomposition/condensation steps, produced at $450{ }^{\circ} \mathrm{C}$ denoted as EMIM-TCB-450 (B, 8.4; C, 36.2; N, 27.0; $\mathrm{H}, 3.6$ ), shows a drastically reduced hydrogen, nitrogen and carbon content compared to EMIM-TCB (B, 4.8; C, 53.1; N, $37.2 ; \mathrm{H}, 4.9)$, whereas the relative boron content has clearly increased. This is in accordance with a suggested decomposition mechanism of ethene or HCN and alkylcyanide elimination. With increasing temperatures of up to $1000{ }^{\circ} \mathrm{C}$ the loss of hydrogen and nitrogen continues, whereas the carbon and boron content relatively increase $(\mathrm{B}, 11.9 ; \mathrm{C}, 39.1 ; \mathrm{N}, 17.5 ; \mathrm{H}, 2.4)$. The overall mass sum of the presented elements $(\mathrm{B}, \mathrm{C}, \mathrm{N}$ and $\mathrm{H})$ does not reach $100 \%$, most likely due to the formerly described postsynthetic oxidation. Up to $1000{ }^{\circ} \mathrm{C}$ the products are therefore best described as $\mathrm{BCN}(\mathrm{O})$ materials, with the oxygen coming from partial post-oxidation.

At temperatures exceeding $1000{ }^{\circ} \mathrm{C}$, the product starts to be a "BCN material". Obviously, the CNB units rearrange to a more stable aromatic arrangement, and oxygen can be released $(\mathrm{B}$, 17.4; C, 56.5; N, 19.0; H, 0.14), which explains the composition step at this temperature in the diagram (Fig. 3).

While in the corresponding reference samples of nitrogendoped carbon the nitrogen content drastically decreases with increasing temperatures, the presence of boron stabilises the nitrogen within the structure. At such high temperatures, a ratio of $1: 1$ between $\mathrm{B}$ and $\mathrm{N}$ is approached. This well-known observation is due to the very strong $\mathrm{B}-\mathrm{N}$ bond, which also makes boron nitrides chemically and thermally extraordinarily stable. This obviously also holds true for B-N in a covalent carbon pool. The final material, prepared at $1400{ }^{\circ} \mathrm{C}$, has the composition of $\mathrm{BC}_{3.1} \mathrm{~N}_{0.96}$ ( $\mathrm{B}, 16.5 ; \mathrm{C}, 56.67 ; \mathrm{N}, 20.44 ; \mathrm{H}, 0.83$ ).

Thermogravimetric analysis coupled with infrared spectroscopy (TG-IR) has been employed to investigate the outgoing 

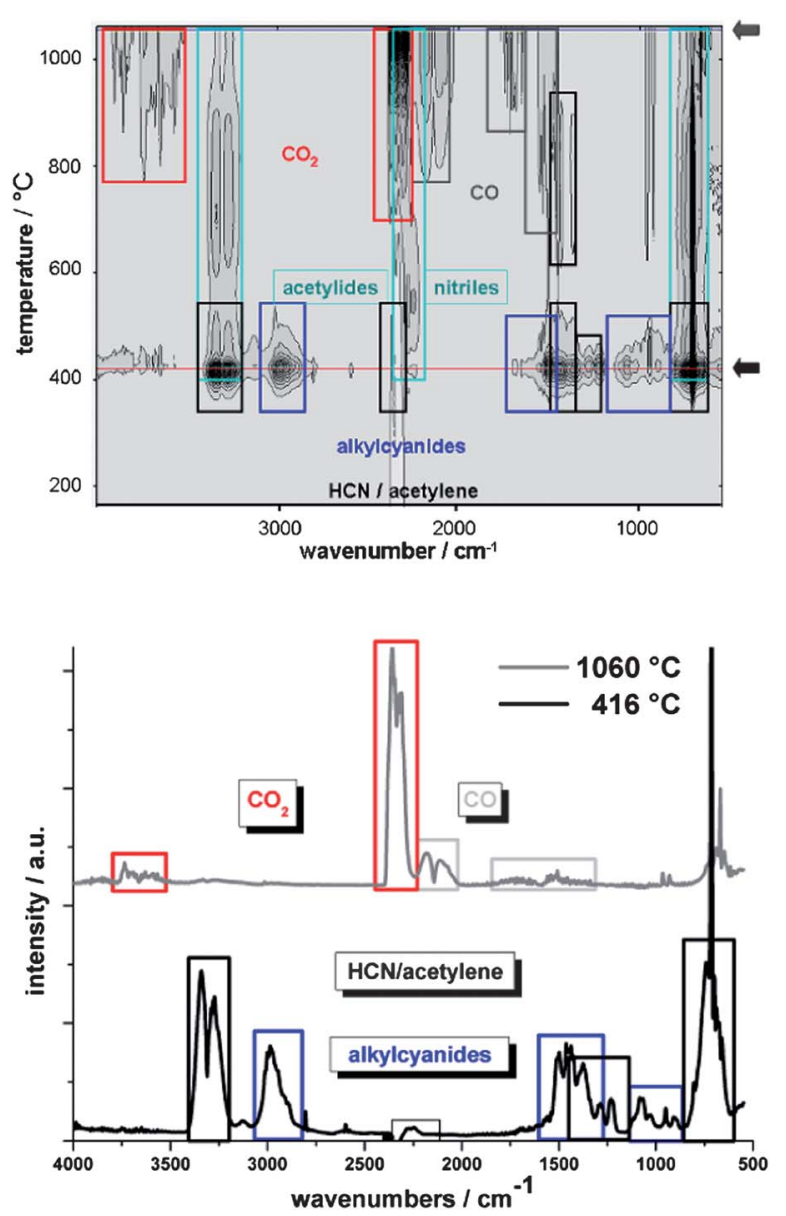

Fig. 4 2D contour plot of TG-IR spectra of the decomposition headgas of EMIM-TCB (up). Illustration of characteristic IR spectra of the main volatile decomposition products of EMIM-TCB (down).

volatile decomposition products (Fig. 4). In accordance with the discussion of the TGA, where a strong mass loss appeared at $416{ }^{\circ} \mathrm{C}$, intensive infrared signals can be detected in the range of this temperature. Pronounced peaks at this point are mainly found in the fingerprint region and in between $2800 \mathrm{~cm}^{-1}$ and $3400 \mathrm{~cm}^{-1}$. With increasing temperature almost continuous signals of lower intensity in the region of $2000-2500 \mathrm{~cm}^{-1}$ and $600-800 \mathrm{~cm}^{-1}$ are obtained. At high temperatures above $900{ }^{\circ} \mathrm{C}$ the signals at $2000-2500 \mathrm{~cm}^{-1}$ are strongly increased. Across the whole temperature range an impurity $\mathrm{CO}_{2}$ band (2300-2400 $\mathrm{cm}^{-1}$ ) with negative intensity has to be taken into account. Most likely, this originates from baseline subtraction achieved with impurities in the nitrogen gas flow.

Fig. 4 left illustrates the described results in a two dimensional contour plot. The observed signals herein are already assigned to decomposition products. In Fig. 4 right the single spectra at representative temperatures of $416^{\circ} \mathrm{C}$ and $1060{ }^{\circ} \mathrm{C}$ are presented.

The characteristic peak sets of HCN (black) and acetonitrile/ propionitrile (alkylnitriles, blue) are observed to be responsible for the strong decomposition step at $416{ }^{\circ} \mathrm{C}$. Interestingly, some of the expected decomposition products are not found in the experiments, e.g. the corresponding imidazole signals are not observed, indicating that these compounds remain in the condensed phase. This is in sharp contrast to all other
$N, N^{\prime}$-dialkylimidazolium ionic liquids. We attribute this to the preservation of a partial ionic character at this stage, presumably due to a stabilisation by back-binding of the liberated electrondeficient boron to the free imidazole nitrogen lone pair. A retro Diels-Alder decomposition of imidazole can be imagined as well, although its occurrence below $550{ }^{\circ} \mathrm{C}$ would contradict the results of Ohtani et $_{\text {al. }}{ }^{52}$

Astonishing is the occurrence of alkine signals (also black, but characteristic at $\sim 1250 \mathrm{~cm}^{-1}$ ) at these temperatures, while alkenes are not detected at all. The absence of alkenes practically excludes Hofmann elimination as a major reaction channel. Harsh conditions and metal catalysts are usually applied for the oxidative dehydrogenation of alkanes, ${ }^{58}$ while acetylene formation occurs here rather spontaneously, presumably in some retro Diels-Alder type reaction scheme not decomposing, but rearranging the imidazole ring. With increasing temperature, the characteristic signals of acetylene and cyanides are observed at a much lower intensity, speaking for the onset of effective cycloaddition reactions. The appearing, slightly red-shifted $\mathrm{C}-\mathrm{N}$ stretch signals are still characteristic for cyanides, but remain unassigned relative to known compounds in the literature.

It was already speculated that the improved stability of the TCB anion, compared to other common anions, delays the process of decomposition to temperatures where even the very stable imidazole structure undergoes structural rearrangements and cross-linking towards a non-evaporating solid. This may also explain why Lee et al. achieved a solid mass from the pyrolysis of ionic liquids without cyano-containing anions, ${ }^{17}$ contrary to the decomposition model of Paraknowitsch. ${ }^{46,59}$ As a fact of the measurement we also have to consider missing IRinactive species or signals. For instance molecular hydrogen and nitrogen, often released from organic materials at high temperatures, are not detectable by this method. The results of the lower temperature range lead to a first decomposition scheme (Fig. 5). Undetected products are shown in grey.

Between 800 and $1000^{\circ} \mathrm{C}$ elemental analysis is showing a step, due to the change of oxygen content. At these temperatures (above $\sim 800{ }^{\circ} \mathrm{C}$ ), carbon monoxide and carbon dioxide are indeed detected, with the fragmentation intensity increasing with temperature. Oxygen is not expected to be a part of the ideal reaction scheme, but the highly oxophilic boron created within the first fragmentation products obviously reacts with oxygen/ water impurities of the IL or the carrier gas of the TG-IR measurements. This oxygen is removed again in later stages with some of the carbon of the structure ("inner carbothermal reduction"). The release of $\mathrm{CO}$ and $\mathrm{CO}_{2}$ is in perfect accordance

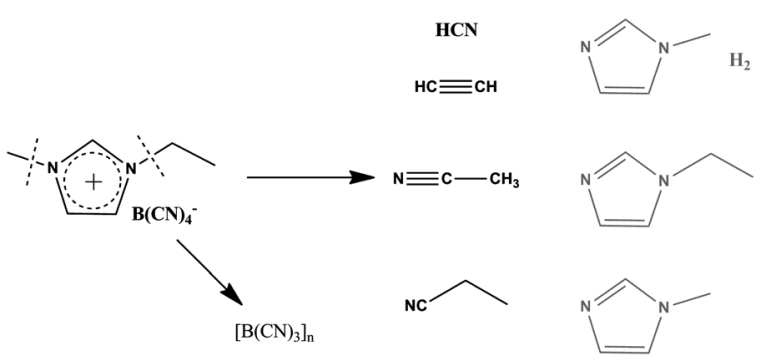

Fig. 5 Decomposition scheme for the "low" temperature $\left(<600{ }^{\circ} \mathrm{C}\right)$ evolution of volatiles at the pyrolysis of EMIM-TCB. 
with the observations from elemental analysis, pointing to the formation of pure $\mathrm{BCN}$ materials only at high temperatures. From previous TG-MS studies it can be expected that molecular hydrogen and nitrogen are released within this typical process of carbonisation/rearrangement as well. ${ }^{60}$

Further information was gained from FT-IR spectroscopy on the products synthesised at 450, 600, 800 and $1000{ }^{\circ} \mathrm{C}$ (Fig. 6). The spectrum of EMIM-TCB-450 (grey) clearly shows the appearance of a strong and broad shoulder developed at 2000$3750 \mathrm{~cm}^{-1}$. The characteristic imidazole signals in the fingerprint region are retained, showing that indeed at least a significant fraction of imidazoles remain structurally intact within the first formed solid. At the same time the mentioned signals appear strongly broadened. The shoulder might be due to $\mathrm{N}-\mathrm{H}$ vibrations and therefore points to events like the protonation of $\mathrm{N}$-alkylimidazoles. The broadened fingerprint region indicates condensation towards a $\pi$-conjugated polyimidazole-type of network. In fact obvious similarities to the vibrational spectrum of poly-bisimidazole-5,5'-diyl are observed. ${ }^{61}$

The second and - as previously reported - most relevant material generating reaction is the cycloaddition of the cyanides, e.g. the triazine building reaction. The characteristic $\mathrm{C} \equiv \mathrm{N}$ stretch signal $\left(2200-2260 \mathrm{~cm}^{-1}\right)$ can still be detected in EMIMTCB-450 (grey) and EMIM-TCB-600 (blue), indicating the preservation of non-reacted cyano-functions. However, the ongoing cycloaddition is evidenced by the successive disappearance of this characteristic peak. In accordance with the conclusions from TG-IR measurements, polymeric imidazoles interlinked with aromatic addition reactions provoke an intermixed network. The intensity of the $\mathrm{N}-\mathrm{H} / \mathrm{O}-\mathrm{H}$ band and the characteristic fingerprint region successively decrease with increasing temperatures, indicating the carbonisation of the whole material. This is in accordance with the steady reduction in the amount of hydrogen and nitrogen in elemental analysis, whereas the carbon content slightly increases. For EMIM-TCB800 (red) no functional groups, namely the broad N-H/O-H vibrations (2000-3750 $\left.\mathrm{cm}^{-1}\right)$ and cyanide signals (2200-2260 $\mathrm{cm}^{-1}$ ), can be detected anymore. This is the typical situation for carbonised materials after the completion of cycloadditions.

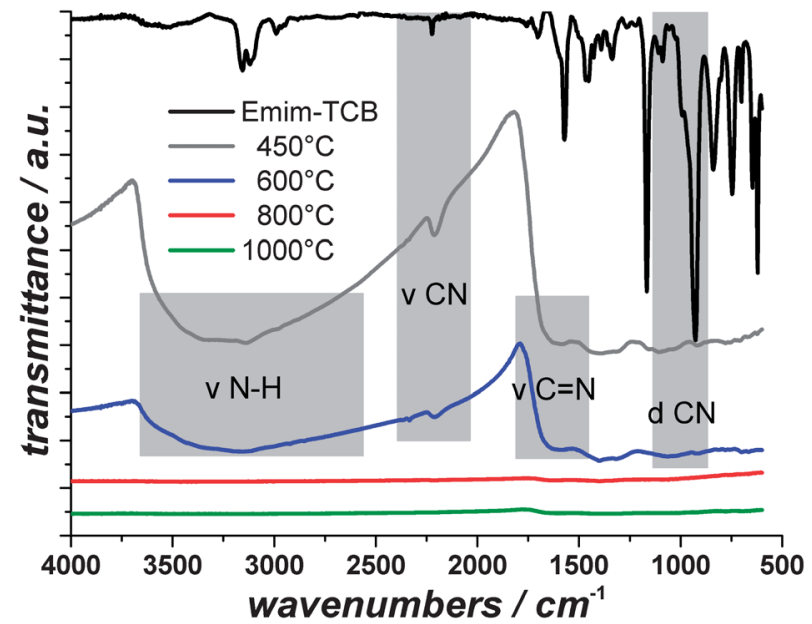

Fig. 6 FT-IR spectra of the solid product from pyrolysis of EMIM-TCB at different temperatures.
With still increasing temperatures, conditions for bond pyrolysis and collective structural rearrangements are approached. The accompanied loss of the final functional groups leads to extended aromatization and coupled formation of the ultimate $\mathrm{BCN}$ material.

\section{(2) Structural analysis}

Carbon $(\mathrm{C})$ and the isoelectric boron nitride $(\mathrm{BN})$ both show structurally equivalent allotropes, as well as amorphous and turbostratic phases. Nitrogen-doped carbon from ionic liquid precursors is usually obtained as $\mathrm{sp}^{2}$-hybridised graphitic carbon. Considering the planar cyano-containing anion dicyanamide and the likewise condensed triazine network this could be expected. In the case of tetrahedral coordinated TCB anions, thus $\mathrm{sp}^{3}$-hybridised boron, the starting situation is different. To get an idea of the actual morphology of the produced BCN material, Raman spectroscopy, electron energy loss spectroscopy (EELS) and wide angle X-ray scattering (WAXS) were applied.

The Raman spectrum of EMIM-TCB-1400 obtained by irradiation with a green laser (532 nm) clearly indicates graphite-like material (Fig. 7). The G-band appears at $1605 \mathrm{~cm}^{-1}$, while the D-band, which is also the $\mathrm{E}_{2 \mathrm{~g}}$ band for unsymmetrical systems such as h-BN, shows up at $1343 \mathrm{~cm}^{-1}$. The D-band is even broader than the G-band, obviously caused by the presence of both the asymmetry of B-N bonds and defect sites in the graphitic structure. At higher wavenumbers, second-order scattering shows the respective overtone bands $\mathrm{D}^{*}$ and $\mathrm{G}^{*}$ as well as combination oscillations. The D-band is red shifted by $27 \mathrm{~cm}^{-1}$, whereas the $\mathrm{G}$-band is blue shifted by $32 \mathrm{~cm}^{-1}$. The energetic positions of the signals are determined by the bond strength. $\mathrm{C}-\mathrm{C}$ bonds are weaker than B-N bond and shift the h-BN-type D-band to lower energies. The opposite influence is found for $\mathrm{B}-\mathrm{N}$ aromatization expressed in the graphite-type G-band. Both shifts together indicate the coupling of $\mathrm{B}, \mathrm{C}$ and $\mathrm{N}$ bonds and therefore the homogeneous character of the materials, which can consequently be denoted as graphitic boron carbon nitride (g-BCN).

The EELS mode in a TEM can perform structural and chemical composition studies at the nanometer scale. Respective

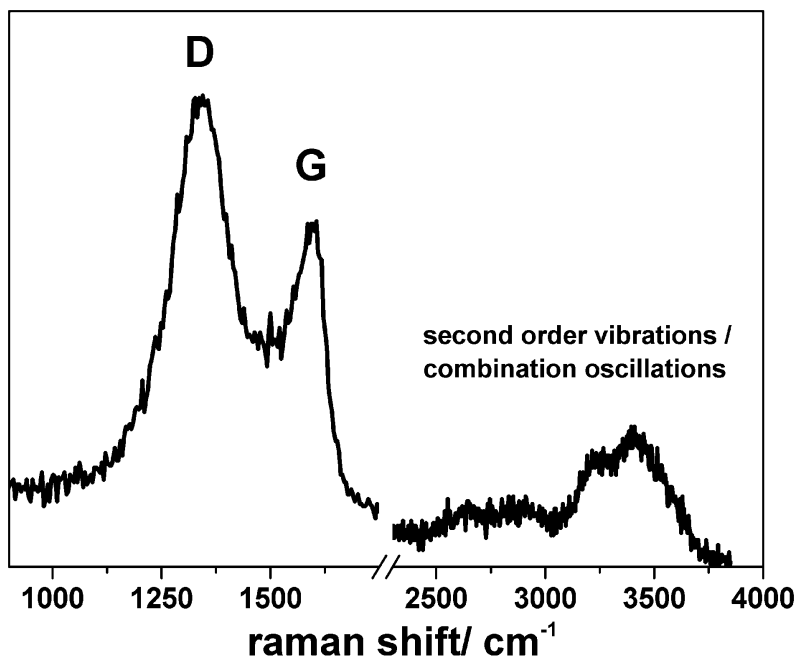

Fig. 7 Raman spectrum of EMIM-TCB-1400 measured with green laser $(\lambda=532 \mathrm{~nm})$. 


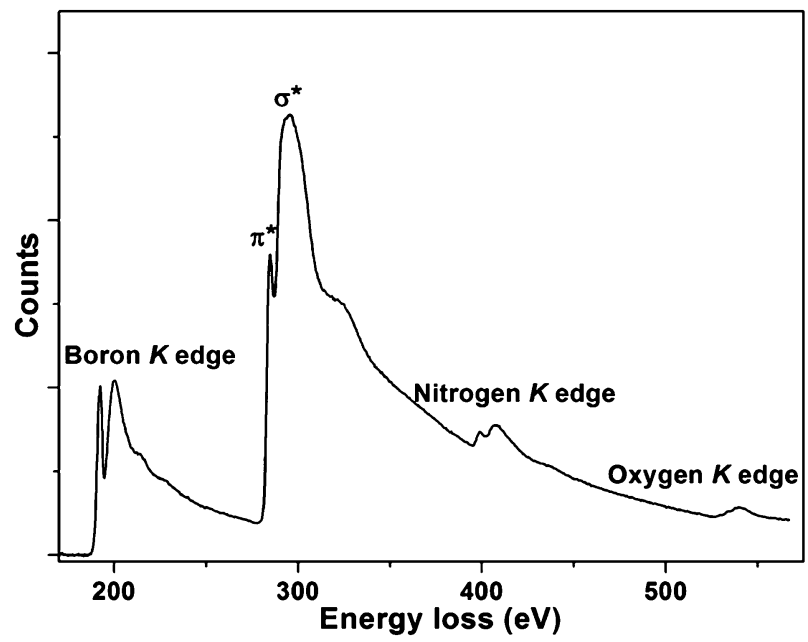

Fig. 8 EELS spectrum of the core loss region of boron, carbon, and nitrogen within EMIM-TCB-1400.

measurements of the core loss region give access to the chemical and electronic structure. Measurements of EMIM-TCB-1400 were applied to provide evidence for the hybridisation of atoms and the homogeneity of the material. As an indication of the homogeneity of the sample, the chemical composition measured by the spatially high resolved $(\sim 1 \mathrm{~nm})$ EELS reflects the bulk composition of EMIM-TCB-1400. The spectral results, reflecting the electronic environment of each atom (Fig. 8), indeed support the concepts of graphitic incorporation of all three elements, with very sharp $\pi^{*}$-transitions, typically for delocalised $\pi$-electron pools. The spectra are typical for a well-defined structure with long-range $\mathrm{sp}^{2}$-hybridisation. This especially has to be underlined for the B-atoms, which seem to be conjugated to larger extents.

WAXS measurements additionally prove the graphitic structure (Fig. 9/left). The ongoing condensation of the polymeric $\mathrm{BCN}$ system at higher temperatures towards the graphitic material can be nicely followed by the corresponding WAXS patterns depending on the condensation temperature. With increasing temperature (from $600{ }^{\circ} \mathrm{C}$ to $1300{ }^{\circ} \mathrm{C}$ ), the typical broadened (002) and (100) peaks, characteristic for inter- and intraplane distances in graphitic materials, develop. In contrast to nitrogen-doped graphitic carbons, the development of graphitic ordering and the coupled strong increase and sharpening of the peaks are only observed above $1000^{\circ} \mathrm{C}$. The loss of oxygen starting at such high temperatures according to TG-IR/ elemental analysis results can be expected to be the reason for this late onset. Oxygen stabilizes tetragonal, $\mathrm{sp}^{3}$-hybridised boron which will hinder the formation of the graphitic morphology.

The typical patterns for graphitic carbons are found at $1400^{\circ} \mathrm{C}$ (Fig. 9/right). Comparable with IL-derived nitrogen-doped carbon materials, broadened $(002)$ at $2 \theta=24.3^{\circ}(d=3.64 \AA)$, $(100)$ - peaks at $2 \theta=43.2^{\circ}(d=2.05 \AA)$ and $(110)$ - peaks at $2 \theta=$ $78.9^{\circ}(d=1.21 \AA)$ are obtained. The observation of the (110) peak is rare and indicates the high conjugation within the material. A certain amount of broadening and peak shifting can be explained by the presence of different heteroelement bonds in $\mathrm{B}_{x} \mathrm{C}_{y} \mathrm{~N}_{x}$, but it is also due to the presence of curvature. Notably,
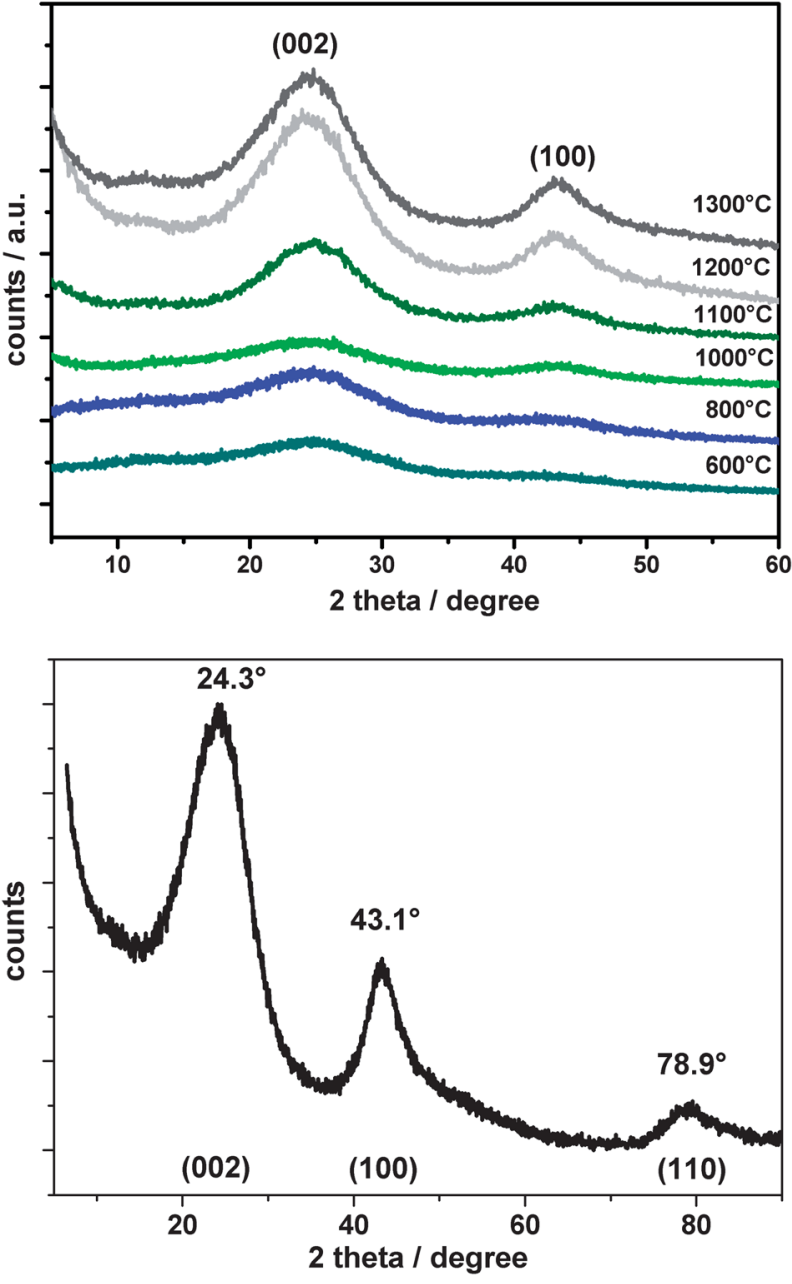

Fig. 9 WAXS-patterns of pyrolysed EMIM-TCB depending on carbonisation temperature (up) and of EMIM-TCB-1400 (down).

the (002) peak is shifted towards smaller angles, indicating a larger interlayer distance of $3.64 \AA$ compared to $3.33 \AA$ for h-BN and $3.35 \AA$ for graphite. ${ }^{2,8,62}$ All features of the diffractograms were retained in nitrogen-doped carbon, underlining the structural similarities of the IL-based materials, with no indications for multiple phases.

X-ray photoelectron spectroscopy (XPS) experiments were also applied (Fig. 10).

The measurements revealed a chemical composition of the boron carbon nitride of $\mathrm{B}_{1.42} \mathrm{C}_{3.1} \mathrm{~N}$. As XPS is a surface-sensitive technique, the comparison with the elemental analysis results $\left(\mathrm{BC}_{3.1} \mathrm{~N}_{0.96}\right)$ indicates an enrichment of boron close to the surface. Additionally, $6.4 \%$ of oxygen is detected, which is also highly enriched at the surface. Importantly, as the metal-free synthetic procedure promises, no metal impurities such as iron are found.

With increasing synthesis temperature the XPS signals are clearly shifted to lower binding energies. This indicates a higher electron density, presumably due to extended aromatization. The B 1s spectra mainly show two peaks. While BI ( $\mathrm{B}_{1000} \mathrm{I} @ 191.1 \mathrm{eV}$; $\mathrm{B}_{1400} \mathrm{I} @ 191.0 \mathrm{eV}$ ) is strongly increased at $1400{ }^{\circ} \mathrm{C}$, becoming the dominant peak, BII B B $1000 \mathrm{II} @ 192.6$ eV; B ${ }_{1400} \mathrm{II} @ 192.7$ eV) rapidly decreases in intensity with increasing temperature. BI can 


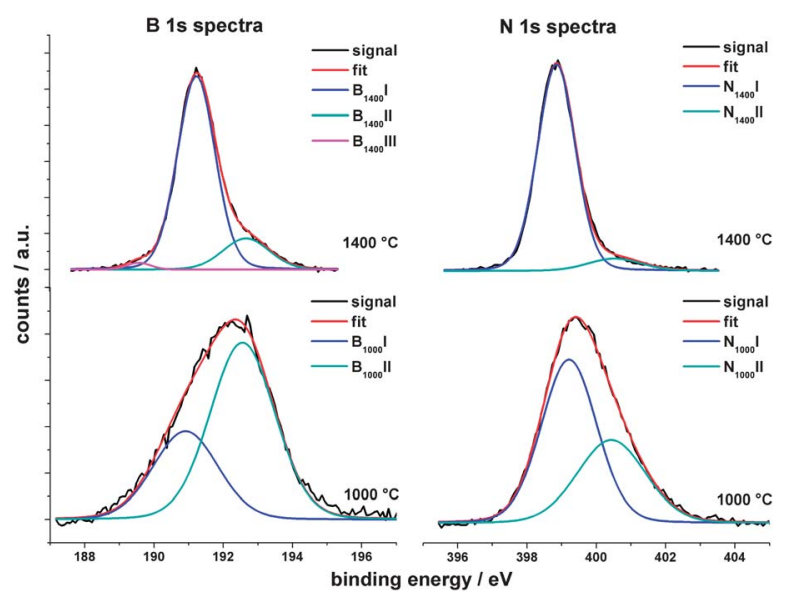

Fig. 10 High resolution XPS spectra (B 1s and N 1s) of EMIM-TCB1000 and EMIM-TCB-1400.

be assigned to the $\mathrm{BCN}$ binding motive, while $\mathrm{BII}$ is traditionally assigned to oxygenated boron (B-O). A third, but comparably weak peak at $189.8 \mathrm{eV}\left(\mathrm{B}_{1400} \mathrm{III}\right)$ is observed for EMIM-TCB1400 , assigned to $\mathrm{a}-\mathrm{C}_{3}$ binding motif (boron without nitrogenbond).

The N 1s spectra are composed of two peaks. NI is dominating, but gets even more intense at higher temperatures. Again, the peak can be denoted as the characteristic BCN peak at 398.8 $\mathrm{eV}\left(\mathrm{N}_{1000} \mathrm{I} / \mathrm{N}_{1400} \mathrm{I}\right)$. A low fraction of (pyrrolic-type) nitrogen bound to carbon can be assigned to the peak NII ( $\mathrm{N}_{1000} \mathrm{II} @ 400.4 ;$ eV N $1400 \mathrm{II} @ 400.5 \mathrm{eV}$ ).

Together, the XPS data clearly support our model that the release of oxygen-containing volatiles (i.e. $\mathrm{CO}_{2}$ and $\mathrm{CO}$ ) allows the rearrangement towards graphitic boron carbon nitride. XPS also supports the structural incorporation of both $\mathrm{B}$ and $\mathrm{N}$ into the graphitic structure well. Contrary to the precursor, where boron is solely bound to carbon, most boron atoms in the final material are also bound to nitrogen, i.e. the local bonds are reshuffled. After high temperature treatment the remaining nitrogen is also predominantly bound to boron. This underlines the isoelectric concept i.e. BN moieties integrated into graphitic carbon are highly stable, while a potential statistical incorporation of the dopants is much less favourable. The higher abundance of boron versus nitrogen at the surface (measured with XPS) compared to the bulk (measured with elemental analysis) can be explained by a "surface pull" due to oxygen, i.e. a weak surface oxidation or boron carbon nitride. Oxygen-terminated boron is stable up to temperatures above $1000{ }^{\circ} \mathrm{C}$, whereas nitrogen not bound to boron is readily released, causing the surface depletion of $\mathrm{N}$. The appearance of the $\mathrm{B}_{1400} \mathrm{III}$ peak at $1400{ }^{\circ} \mathrm{C}$ indicates the conversion of surface terminating $\mathrm{B}-\mathrm{O}$ bonds at least partly into $\mathrm{B}-\mathrm{C}$ at even higher temperatures. Regarding the overall elemental composition of the final boron carbon nitride $\left(\sim \mathrm{BC}_{3} \mathrm{~N}\right)$ we find a relatively higher carbon content as compared to yet reported molecule pyrolysis routes. ${ }^{27-30}$ Typically, the carbon is more easily eliminated from the material compared to the $\mathrm{BN}$ pairs. We surmise the present precursor chemistry with the boron atom strongly bonded to four carbon atoms in the TCB anion to be the cause for this interesting property.

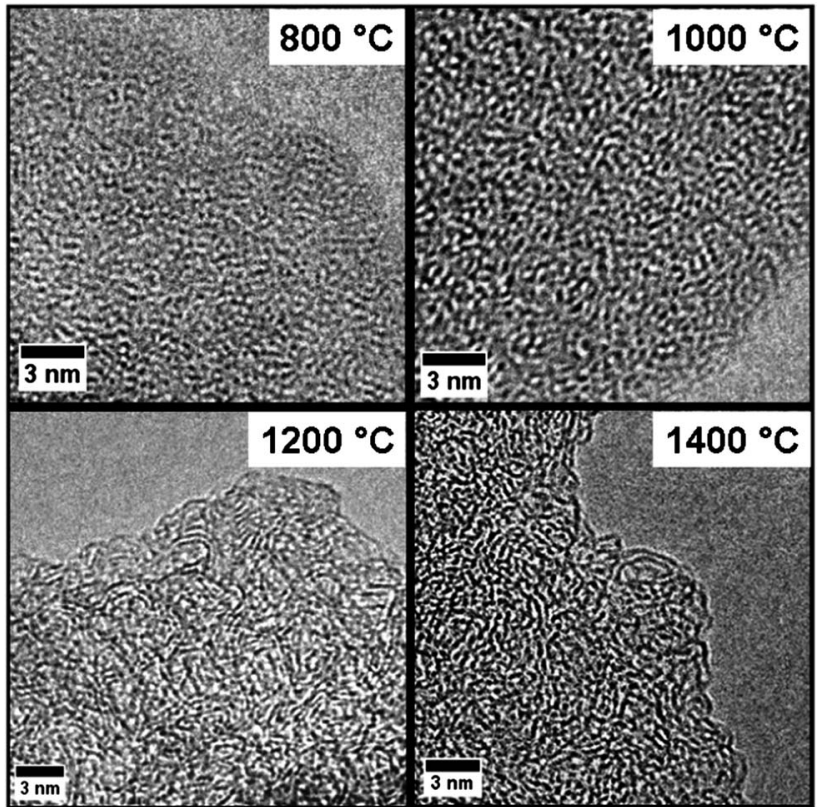

Fig. 11 HRTEM images of the solid products of the carbonisation of EMIM-TCB synthesised at 800, 1000, 1200 and $1400{ }^{\circ} \mathrm{C}$.

The local structure was finally investigated by HRTEM. Fig. 11 compares the products derived at temperatures of 800 , 1000,1200 and $1400{ }^{\circ}$ C. EMIM-TCB-800 and EMIM-TCB-1000 can hardly be distinguished from amorphous carbon (see Appendix). The image of EMIM-TCB-1200 indicates the development of different curved morphologies, most likely being bent graphitic layers. Further heat treatment leads to a cauliflowerlike appearance, where the curvature of the layers remains the same. The condensed bulk material is obviously made up of intermingled, curved nanosheets. The lack of a long-range translational order is in perfect agreement with the presented WAXS data, while the curvature, which is comparable to carbon nanotubes or carbon-onions explains the increased interlayer distance and the shifted (002) peak as well the increased intensity and broadening of the Raman-D-band. The structures are indeed very similar to nitrogen-doped carbons from ILs.

\section{(3) Electronic properties}

IL-based nitrogen-doped carbon materials, even though more disordered, have been reported to exhibit advanced electrical conductivity compared to graphite powder. ${ }^{31}$ Crystalline, graphitic $\mathrm{B}_{x} \mathrm{C}_{y} \mathrm{~N}_{z}$ materials were reported to have a basal-plane resistivity of $7.81 \times 10^{-3} \Omega \mathrm{m}(\mathrm{BCN}(\mathrm{H}))$ and $0.11 \times 10^{-3} \Omega \mathrm{m}$ $\left(\mathrm{BC}_{3} \mathrm{~N}(\mathrm{H})\right)$ at room temperature, ${ }^{61,63}$ which is between typical semiconductors and the semimetallic graphite ( $\rho$ (silicon): $6.4 \times$ $10^{2} \Omega \mathrm{m} @ 20^{\circ} \mathrm{C} ; \rho$ (graphite, basal plane): $2.5-5 \times 10^{-6} \Omega \mathrm{m} @$ $\left.20{ }^{\circ} \mathrm{C}\right) .{ }^{64}$ Knowing that h-BN, being a structural part of the BCN material, is an insulator, this value is comparably low. To learn more about the electronic behaviour of BCN (EMIM-TCB-1400) in direct comparison with nitrogen-doped carbon prepared from the ionic liquid $N$-butyl-3-methylpyridinium dicyanamide (BMPdca) at $1000{ }^{\circ} \mathrm{C},{ }^{17}$ samples were spark-plasma sintered to homogeneous monolithic pellets (Fig. 12, inset) and then characterised in terms of the Seebeck coefficients and resistivity. 


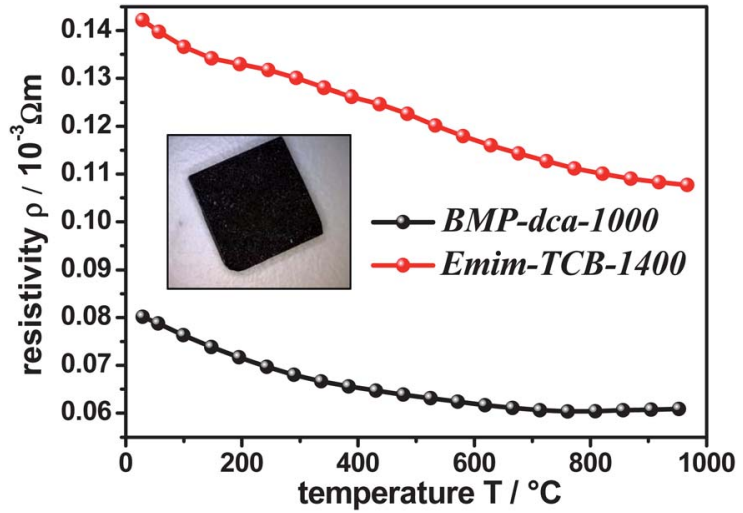

Fig. 12 Electrical resistivity measurement of EMIM-TCB-1400 and BMP-dca-1000 between 25 and $950{ }^{\circ} \mathrm{C}$ using standard 4 point probe setup on a plasma sintered monolith $\left(\sim 1 \mathrm{~cm}^{2}\right)$.

The Seebeck coefficients $\alpha$ (see Appendix) indicate the expected n-type character of the nitrogen-doped carbon $(\alpha<0)$, while the $\mathrm{B} / \mathrm{N}$-doped carbon (EMIM-TCB-1400) turns out to be a p-type semiconductor $(\alpha>0)$. This can be related to the slightly higher boron content exceeding the nitrogen content within the sample. ${ }^{63}$ The low values of Seebeck coefficients ( $\alpha$ (nitrogendoped carbon): -2 to $(-10) \mu \mathrm{V} \mathrm{K}^{-1} ; \alpha$ (EMIM-TCB-1400): $\left.10-30 \mu \mathrm{V} \mathrm{K}^{-1}\right)$ are typical for a high concentration of charge carriers, one of the two main factors for electrical conductivity.

The electrical resistivity in the temperature range from $0{ }^{\circ} \mathrm{C}$ to $950{ }^{\circ} \mathrm{C}$ reflects the semiconducting behaviour of both products, showing the typical decreasing resistivity with increasing temperature (Fig. 12). For semiconductors the electrical resistivity of the materials are very low, even when compared to conduction soots $\left(\rho\right.$ (amorphous carbon) $=50-80 \times 10^{-3} \Omega \mathrm{m} @$ $\left.20{ }^{\circ} \mathrm{C}\right) .{ }^{31,64}$ BMP-dca-1000 has a resistivity of $\sim 0.08 \times 10^{-3} \Omega \mathrm{m}$ (a) room temperature, while EMIM-TCB-1400 $\left(\rho \sim 0.14 \times 10^{-3}\right.$ $\Omega \mathrm{m} @$ room temperature) shows an electrical resistivity which is only 1.75 times less than that of the nitrogen-doped carbon, therefore even being in the range of crystalline $\mathrm{BCN}$ materials. ${ }^{65}$

These characteristics indeed make the present materials highly promising for various potential applications. Chemical functionalities at the surface, such as the BCN binding motif, might induce interesting reactivity due to the acid and base character. At the same time, a high electrical conductivity tailors the materials especially for the fields of electrochemistry and electrocatalysis.

\section{Conclusion}

An ionic liquid with the tetracyanoborate counterion was investigated as a precursor for carbon materials with simultaneous $\mathrm{N}$ - and $\mathrm{B}$-doping, i.e. to make graphitic boron carbon nitrides. Whilst the $\mathrm{C}-\mathrm{N}$ based systems were already mechanistically investigated in more detail, the $\mathrm{B}-\mathrm{C}-\mathrm{N}$ system has not been studied yet. Indeed, it was found to show some relevant peculiarities. EMIM-TCB exhibits a thermal stability above $400{ }^{\circ} \mathrm{C}$, which could be related to the low nucleophilicity and low basicity of the anion. Interestingly, the usual decomposition via Hofmann elimination could be completely suppressed, while splitting of the comparably weakest bond, the B-C linkage, induces reverse Menschutkin reaction at higher temperatures. The resulting imidazole fragments are not volatile, but presumably back-bonded to the boron fragments, which accordingly leads to improved carbonization yields $(25.5 \mathrm{wt} \%$ as compared to $13.6 \mathrm{wt} \%$ for EMIM-dca). The intermediary imidazoles formed subsequently polymerise to form a solid phase under $\mathrm{HCN}$ elimination and retro Diels-Alder reactions. We are obviously dealing with the complex formation of an intermixed network consisting of cation and anion based parts. The solid formation in the studied case starts with the formation of a polyimidazoletype network, while structural rearrangements contribute to material formation only in later stages. Carbonisation at $1400{ }^{\circ} \mathrm{C}$ gives finally the graphitic boron carbon nitride with a weakly ordered structure, very similar to the one of ionic liquid based nitrogen-doped carbons. The comparably high temperatures are needed to structurally incorporate the highly oxophilic boron into the graphitic lattice. In contrast to other molecule pyrolysis approaches the final stoichiometry shows a higher carbon content being close to $\mathrm{BC}_{3} \mathrm{~N}$. We conclude that the present precursor chemistry with the boron atom strongly bonded to four carbon atoms in the TCB anion leads to this interesting property. The electronic characterisation of the material shows that it is a p-type semiconductor with low resistivity and high potential for electrode applications.

\section{Acknowledgements}

Dr Jérôme Roeser and Sören Selve (TU Berlin) are thanked for TGA-DSC and HRTEM measurements. Carmen Serra (Vigo) is thanked for fast XPS measurements. D. Gautam and M. Engenhorst would like to thank Markus Winterer, Gabi Schierning and Roland Schmechel for their support in conducting the spark plasma sintering experiments and thermoelectric measurements.

\section{References}

1 J. Kouvetakis, R. B. Kaner, M. L. Sattler and N. Bartlett, J. Chem. Soc., Chem. Commun., 1986, 1758.

2 H. J. Burch, J. A. Davies, E. Brown, L. Hao, S. A. Contera, N. Grobert and J. F. Ryan, Appl. Phys. Lett., 2006, 89, 143110.

3 S. Glenis, A. J. Nelson and M. M. Labes, J. Appl. Phys., 1999, 86, 4464.

4 Y. Shao, S. Zhang, M. H. Engelhard, G. Li, G. Shao, Y. Wang, J. Liu, I. A. Aksay and Y. Lin, J. Mater. Chem., 2010, 20, 7491.

5 Q. H. Yang, W. H. Xu, A. Tomita and T. Kyotani, Chem. Mater., 2005, 17, 2940.

6 D. P. Kim, C. L. Lin, T. Mihalisin, P. Heiney and M. M. Labes, Chem. Mater., 1991, 3, 686.

7 R. Czerw, M. Terrones, J. C. Charlier, X. Blase, B. Foley, R. Kamalakaran, N. Grobert, H. Terrones, D. Tekleab, P. M. Ajayan, W. Blau, M. Rühle and D. L. Carroll, Nano Lett., 2001, 1, 457.

8 A. C. M. Carvalho and M. C. d. Santos, J. Appl. Phys., 2006, 100, 084305.

9 R. B. Kaner, J. Kouvetakis, C. E. Warble, M. L. Sattler and N. Bartlett, Mater. Res. Bull., 1987, 22, 399.

10 L. S. Panchakarla, K. S. Subrahmanyam, S. K. Saha, A. Govindaraj, H. R. Krishnamurthy, U. V. Waghmare and C. N. R. Rao, $A d v$. Mater., 2009, 21, 4726.

11 S. Maldonado and K. J. Stevenson, J. Phys. Chem. B, 2005, 109, 4707.

12 T. Iwazaki, R. Obinata, W. Sugimoto and Y. Takasu, Electrochem. Commun., 2009, 11, 376. 
13 S.-F. Huang, K. Terakura, T. Ozaki, T. Ikeda, M. Boero, M. Oshima, J.-i. Ozaki and S. Miyata, Phys. Rev. B: Condens. Matter Mater. Phys., 2009, 80, 235410.

14 J.-i. Ozaki, N. Kimura, T. Anahara and A. Oya, Carbon, 2007, 45, 1847.

15 W. Yang, T.-P. Fellinger and M. Antonietti, J. Am. Chem. Soc., 2011, 133, 206.

16 J. P. Paraknowitsch, Dissertation: "Entwicklung von Kohlenstoffmaterialien für Energieanwendungen durch gezielte Modifikation der chemischen Struktur", Universität Potsdam, Potsdam, 2009.

17 J. P. Paraknowitsch, A. Thomas and M. Antonietti, J. Mater. Chem., 2010, 20, 6746.

18 J. P. Paraknowitsch, J. Zhang, D. Su, A. Thomas and M. Antonietti, Adv. Mater., 2010, 22, 87.

19 R. Gadiou, A. Didion, R. I. Gearba, D. A. Ivanov, I. Czekaj, R. Kötz and C. Vix-Guterl, J. Phys. Chem. Solids, 2008, 69, 1808.

20 M. Terrones, H. Terrones, N. Grobert, W. K. Hsu, Y. Q. Zhu, J. P. Hare, H. W. Kroto, D. R. M. Walton, K.-R. Ph, M. Ruhle, J. P. Zhang and A. K. Cheetham, Appl. Phys. Lett., 1999, 75, 3932.

21 M. Terrones, P. Redlich, N. Grobert, S. Trasobares, W.-K. Hsu, H. Terrones, Y.-Q. Zhu, J. P. Hare, C. L. Reeves, A. K. Cheetham, M. Rühle, H. W. Kroto and D. R. M. Walton, Adv. Mater., 1999, 11, 655 .

22 M. Terrones, R. Kamalakaran, T. Seeger and M. Ruhle, Chem. Commun., 2000, 2335.

23 R. Sen, B. C. Satishkumar, A. Govindaraj, K. R. Harikumar, M. K. Renganathan and C. N. R. Rao, J. Mater. Chem., 1997, 7, 2335.

24 R. Czerw, J. Liu and D. L. Carrolla, J. Mater. Res., 2004, 20, 538.

25 L. Zhi, T. Gorelik, R. Friedlein, J. Wu, U. Kolb, W. R. Salaneck and K. Müllen, Small, 2005, 1, 798.

26 A. R. Badzian, T. Niemyski, S. Appenheimer and E. Olkusnik, Khim. Svyaz. Poluprov. Polumetallah., 1972.

27 Y. Goto, M. Sasaki, M. Hashizume and M. Suzuki, J. Eur. Ceram. Soc., 1999, 19, 2695.

28 T. Komatsu and A. Goto, J. Mater. Chem., 2002, 12, 1288.

29 Y. H. Zhao, D. W. Daemen, L. L. Shen, T. D. Schwarz, R. B. Zhu, Y. Bish, D. L. Huang, J. Zhang, J. Shen, G. Qian and T. W. Zerda, J. Mater. Res., 2002, 17, 3139.

30 L.-J. Li, M. Glerup, A. N. Khlobystov, J. G. Wiltshire, J. L. Sauvajol, R. A. Taylor and R. J. Nicholas, Carbon, 2006, 44, 2752.

31 M. Kawaguchi, T. Kawashima and T. Nakajima, Chem. Mater., 1996, 8, 1197.

32 M. Kawaguchi and T. Kawashima, J. Chem. Soc., Chem. Commun., 1993, 14, 1133.

33 R. Riedel, J. Bill and G. Passing, Adv. Mater., 1991, 3, 551.

34 L. Ci, L. Song, C. Jin, D. Jariwala, D. Wu, Y. Li, A. Srivastava, Z. F. Wang, K. Storr, L. Balicas, F. Liu and P. M. Ajayan, Nat. Mater., 2010, 9, 430.

35 K. Raidongia, A. Nag, K. P. S. S. Hembram, U. V. Waghmare, R. Datta and C. N. R. Rao, Chem.-Eur. J., 2010, 16, 149.

36 C. N. R. Rao and A. Nag, Eur. J. Inorg. Chem., 2010, 2010, 4244.

37 Y. Chen, J. C. Barnard, R. E. Palmer, M. O. Watanabe and T. Sasaki, Phys. Rev. Lett., 1999, 83, 2406.
38 M. O. Watanabe, S. Itoh, T. Sasaki and K. Mizushima, Phys. Rev. Lett., 1996, 77, 187.

39 W. Wang, Y. Bando, C. Zhi, W. Fu, E. Wang and D. Golberg, J. Am. Chem. Soc., 2008, 130, 8144.

40 J. D. Guo, C. Y. Zhi, X. D. Bai and E. G. Wang, Appl. Phys. Lett., 2002, 80, 124.

41 D. Portehault, C. Giordano, C. Gervais, I. Senkovska, S. Kaskel, C. Sanchez and M. Antonietti, Adv. Funct. Mater., 2010, 20, 1827.

42 P. R. L. Malenfant, J. Wan, S. T. Taylor and M. Manoharan, Nat. Nanotechnol., 2007, 2, 43.

43 A. Vinu, M. Terrones, D. Golberg, S. Hishita, K. Ariga and T. Mori, Chem. Mater., 2005, 17, 5887.

44 W. Lei, D. Portehault, R. Dimova and M. Antonietti, J. Am. Chem. Soc., 2011, 133, 7121.

45 Y. Wang, H. Li, J. Yao, X. Wang and M. Antonietti, Chem. Sci., 2010, 2, 446.

46 J. S. Lee, H. Luo, G. A. Baker and S. Dai, Chem. Mater., 2009, 21, 4756.

47 X. Wang and S. Dai, Angew. Chem., Int. Ed., 2010, 49, 6664.

48 S. A. Forsyth, J. M. Pringle and D. R. MacFarlane, Aust. J. Chem., 2004, 57, 113.

49 C. L. Hussey, Adv. Molten Salt Chem., 1983, 5, 185.

50 N. Fechler, T.-P. Fellinger and M. Antonietti, Adv. Mater., 2012, DOI: 10.1002 /adma.201203422.

51 T. J. Wooster, K. M. Johanson, K. J. Fraser, D. R. MacFarlane and J. L. Scott, Green Chem., 2006, 8, 691.

52 H. Ohtani, S. Ishimura and M. Kumai, Thermal Decomposition Behaviors of Imidazolium-type Ionic Liquids Studied by PyrolysisGas Chromatography, Japan Society for Analytical Chemistry, Tokyo, Japan, 2008, vol. 24.

53 E. Bernhardt, G. Henkel and H. Willner, J. Heterocycl. Chem., 2000, 626, 560 .

54 D. Williams, B. Pleune, J. Kouvetakis, M. D. Williams and R. A. Andersen, J. Am. Chem. Soc., 2000, 122, 7735.

55 T. Küppers, E. Bernhardt, C. W. Lehmann and H. Willner, J. Heterocycl. Chem., 2007, 633, 1666.

56 Z. Chen, F. Yan, L. Qiu, J. Lu, Y. Zhou, J. Chen, Y. Tang and J. Texter, Langmuir, 2010, 26, 3803

57 J. Lu, F. Yan and J. Texter, Prog. Polym. Sci., 2009, 34, 431.

58 D. W. Flick and M. C. Huff, Catal. Lett., 1997, 47, 91.

59 J. S. Lee, X. Wang, H. Luo, G. A. Baker and S. Dai, J. Am. Chem. Soc., 2009, 131, 4596.

$60 \mathrm{~T}$. Yamamoto, T. Uemura, A. Tanimoto and S. Sasaki, Macromolecules, 2003, 36, 1047.

61 H. O. Pierson, Handbook of Carbon, Graphite, Diamond, and Fullerenes: Properties, Processing, and Applications, 1993.

62 D. Mang, H. P. Boehm, K. Stanczyk and H. Marsh, Carbon, 1992, 30, 391.

63 R. A. Serway, Principles of Physics, Saunders College Pub., London, 1998.

64 J. Bill, F. Aldinger, G. Petzow, M. Sloma, J. Maier and R. Riedel, J. Mater. Sci. Lett., 1999, 18, 1513.

65 L. Yang, S. Jiang, Y. Zhao, L. Zhu, S. Chen, X. Wang, Q. Wu, J. Ma, Y. Ma and Z. Hu, Angew. Chem., Int. Ed., 2011, 50, 7132. 